\title{
O INCENTIVO A MICRO E PEQUENA EMPRESA COMO INSTRUMENTO DE GERAÇÃO DE EMPREGOS
}

\section{THE INCENTIVE OF MICRO AND SMALL ENTERPRISE AS AN INSTRUMENT FOR GENERATING EMPLOYMENT}

\author{
${ }^{1}$ Demetrius Nichele Macei \\ ${ }^{2}$ Francelise Camargo de Lima
}

\section{Resumo}

As Microempresas e Empresas de pequeno porte representam um papel importante no desenvolvimento econômico sustentável. A Lei Complementar $\mathrm{n}^{\circ}$ 123/2006, que regulamentou os artigos $146 \S$ único e 179 da $\mathrm{CF} / 88$, demonstra a proteção estatal, pois dispensa um tratamento jurídico diferenciado e simplificado consistente na redução de tributos, de contribuições tributárias, de obrigações administrativas; e facilidades creditícias. As MPEs viabilizam a geração de através do fomento ao empreendedorismo e geram empregos a medida que permanecem no atuando no mercado econômico. A redução de alíquotas de impostos contribui para a manutenção dessas empresas no acirrado mercado econômico e garante a empregabilidade.

Palavras-chaves: Micro e Pequenas Empresas, empregabilidade, incentivo.

\begin{abstract}
The Micro and Small businesses play an important role in sustainable economic development. Supplementary Law No. 123/2006, regulating Articles 146 and $179 \S$ single CF / 88 shows the state protection, because it eliminates a different legal treatment and simplified consistent in reducing taxes, tax contributions, administrative obligations; and credit facilities. MSEs enable the generation by fostering entrepreneurship and create jobs as they remain in acting in the economic market. The reduction of tax rates contribute to the maintenance of these companies in the fierce market economy and ensures employability.
\end{abstract}

Keywords: Micro and Small Enterprises, employment, incentive.

\footnotetext{
${ }^{1}$ Doutor em Direito Tributário pela Pontifícia Universidade Católica de São Paulo, PUC - SP, (Brasil).. Professor de Direito Tributário na graduação, especialização e mestrado no Centro Universitário de Curitiba, UNICURITIBA - PR, (Brasil).É Advogado. E-mail: demetriusmacei@gmail.com

2 Mestranda em Direito Empresarial e Cidadania do Centro Universitário de Curitiba, UNICURITIBA - PR, (Brasil). É Advogada. E-mail: franceliselima@hotmail.com
} 


\section{INTRODUÇÃO}

O enfoque do Direito a luz da Ordem Econômica com o devido respaldo na Constituição Federal de 1988, a qual inseriu princípios claros voltados ao desenvolvimento econômico e à proteção das Micro e Pequenas Empresas, uma questão carece de resposta, a qual consiste em determinar até que ponto os de incentivos fiscais voltados às MPEs são capazes de fomentar o empreendedorismo e a geração de novos empregos?

Em um primeiro momento abordar-se-á conceitos jurídicos a partir da Constituição Federal de 1988 e da legislação infraconstitucional evidenciando um breve histórico da intenção protecionista em relação às MPEs o que justifica a sua importância no âmbito econômico.

Na sequência apresentar-se-á das oportunidades de inclusão laborativa originadas a partir da atividade empresarial, o empreendedorismo e a geração de empregos formais.

Em ato contínuo, abordar-se-á de que forma as MPEs podem ser estimuladas, por meio de incentivos fiscais, a gerar novos postos de trabalho e se os mesmos incentivos servem de estímulo para o trabalhador que está na informalidade se inserir no mercado formal fomentando o empreendedorismo e geração de novos empregos favorecendo po desenvolvimento econômico e possibilitando a inclusão do cidadão no mercado de trabalho.

\section{A MICRO E PEQUENA EMPRESA - CONCEITOS E CONTEXTUALIZAÇÃO}

2.1 A Micro e Pequena empresa na Constituição Federal de 1988

A Constituição Federal de 1988, com o objetivo de favorecer e dispensar um tratamento diferenciado às empresas de micro e pequeno porte, inseriu em seu texto uma nova concepção por entender a importância das mesmas para a ordem econômica. ${ }^{3}$ Com esses novos princípios em vigor, a constituição legitimou a prestação de serviços estatais na medida da necessidade das Pequenas e Microempresas (MPE), e dentro desta perspectiva, prestar de forma adequada a toda população, não implica necessariamente tratar a todos de forma

3 BRASIL. Constituição da República Federativa do Brasil de 1988. Disponível em: <http://www.planalto.gov.br/ccivil_03/constituicao/constituiçao.htm>. Acesso em 11 dez. 2015. 
idêntica, sem traçar qualquer diferenciação, tratamento igual aos iguais e desigual as desiguais. $^{4}$

Visando inserir no contexto legal princípios norteadores da economia, no topo da hierarquia está a CF/88 que assim diz em seu art. 179 da CF/88 assim preconiza:

Art. 179. A União, os Estados, o Distrito Federal e os Municípios dispensarão às microempresas e às empresas de pequeno porte, assim definidas em lei, tratamento jurídico diferenciado, visando a incentivá-las pela simplificação de suas obrigações administrativas, tributárias, previdenciárias e creditícias, ou pela eliminação ou redução destas por meio de lei. ${ }^{5}$

O tratamento jurídico diferenciado e o dever de favorecimento às ME e EPP, desencadeou a necessidade de adequar a legislação infraconstitucional em conformidade com a nova ordem emanada da carta magna.

Anterior a edição a Constituição Federal de 1988, vigorava a Lei $n^{\circ} 7.256 / 84$, a qual apresentava as diferenciações entre as micro e pequenas empresas em relação as demais, referida norma foi revogada em 1999 pela Lei $9.841 .^{6}$ Em um passado não muito distante não existiam qualquer norma que vinculava o Estado na regulação econômica, a regulação não ultrapassava a competência administrativa, não havia intervenção do Estado na economia. ${ }^{7}$

Em 28 de março de 1994 passou a vigorar a Lei no 8.864 de 28 de Março de 1994 onde seu texto previa a alteração dos valores para o enquadramento das microempresas e estabelecia normas relativas ao tratamento diferenciado e simplificado, nos campos administrativo, fiscal, previdenciário, trabalhista; creditício e de desenvolvimento empresarial, bem como inseriu as diferenciações entre empresa de pequeno porte e micro empresa. ${ }^{8}$

A lei do SIMPLES - Sistema Integrado de Pagamento de Impostos e Contribuições das ME e EPP foi criada em 05 de dezembro de 1996 e inseriu na seara jurídica um enquadramento tributário mais benéfico às ME e EPP. A partir da Lei $n^{\circ}$ 9.317/96, houve

\footnotetext{
${ }^{4}$ HACHEM, Daniel Wunder. Direito fundamental ao serviço público adequado e capacidade econômica do cidadão: repensando a universalidade do acesso à luz da igualdade material. A\&C - Revista de Direito Administrativo \& Constitucional, Belo Horizonte, ano 14. N. 55, jan./mar. 2014.

${ }^{5}$ BRASIL. Op. Cit. Disponível em: <http://www.planalto.gov.br/ ccivil_03/ constituicao/ constituiçao. htm>. Acesso em 11 dez. 2015.

6 BRASIL, LEI no. 7.256, DE 27 DE NOVEMBRO DE 1984. Disponível em: http://www.planalto.gov.br/ccivil_03/ leis/_L7256.htm>. Acesso em 11 dez. 2015.

${ }^{7}$ MOREIRA, Egon Bockmann ...

${ }^{8}$ BRASIL. Lei $\mathbf{n}^{\circ} 8.864$ de 28 de Março de 1994. http://www.planalto.gov.br/ccivil_03/leis/L8864.htm>. Acesso em 11 dez. 2015.
} 
uma redução das alíquotas dos tributos bem como uma forma mais simplificada para o recolhimento dos tributos federais, estaduais e municipais. ${ }^{9}$

A Lei $n^{\circ} 9.841$ de 05 de outubro de 1999 estabeleceu a política de compras públicas, onde as micro e empresas de pequeno porte terão preferência para participar de licitações inclusive com a aplicação de processos mais simples. ${ }^{10}$

Com a inserção do parágrafo único do art. 146 da Constituição Federal, por meio da Emenda Constitucional $\mathrm{n}^{\mathbf{0}}$ 42, que passou a exigir uma Lei Complementar visando regulamentar um regime único de arrecadação de impostos e contribuições da União, Estados, Distrito Federal e Municípios, foi criada então a Lei Complementar $n^{\circ} 123$ de 14 de Dezembro de 2006.

A partir de então, com a previsão constitucional inserida nos artigos $146 \S$ único e 179 da CF/88 originou-se a Lei Complementar $n^{\circ}$ 123, de 14 de dezembro de 2006, foi instituído o Estatuto Nacional da Microempresa e da Empresa de Pequeno Porte.

A Lei Geral das microempresas, conhecida como Super Simples, contribui de forma efetiva para a construção de um ambiente sustentável rumo ao desenvolvimento e crescimento das micro e pequenas empresas, pois garante um tratamento jurídico diferenciado, simplificado e favorecido, através da regulamentação do texto constitucional". ${ }^{11}$

As empresas contempladas com as beneficies da Lei Geral das Microempresas são as que atendem os seguintes critérios: a) critério de ordem objetiva, diz respeito, aos níveis de faturamento do agente e seu enquadramento como microempresário; b) critério de ordem subjetiva, referente às circunstancias pessoais do favorecido, devendo o mesmo enquadrar-se nos conceitos de empresário, sociedade empresária ou sociedade simples. ${ }^{12}$ Contudo, há certas restrições e tais casos estão listados no artigo $3^{\circ}, \S 4^{\circ}$, constituindo restrições subjetivas ao tratamento diferenciado e favorecido a ser dispensado às microempresas e empresas de pequeno porte. ${ }^{13}$

Como é possível perceber, a Constituição Federal de 1988 objetivou promover o crescimento econômico considerando o importante papel das MPE.

9 BRASIL, Lei $\mathbf{n}^{\mathbf{0}}$ 9.317, de 5 de Dezembro de 1996. http://www.planalto.gov.br/ccivil_03/leis/L9317.htm>. Acesso em 11 dez. 2015.

${ }^{10}$ BRASIL, Lei $\mathbf{n}^{0}$ 9.841, de 5 de Outubro de 1999. http://www.planalto.gov.br/ccivil_03/leis/L9841.htm>. Acesso em 11 dez. 2015.

${ }^{11}$ BOMFIN, Ana Paula Rocha do. Comentários ao Estatuto Nacional das Microempresas e Empresas de Pequeno Porte - LC 123/2006. 1. Ed. Rio de Janeiro: Lumen Juris, 2007, p.2.

${ }^{12}$ MARINS, James; BERTOLDI, Marcelo M. Simples Nacional: Estatuto da Microempresa e Empresa de Pequeno Porte Comentado. 1. Ed. São Paulo: Revista dos Tribunais, 2007.

${ }^{13}$ MAMEDE, Gladston. Comentários ao Estatuto Nacional da Microempresa e da Empresa de Pequeno

Porte. 1. Ed. São Paulo: Atlas, 2007.Gladston Mamede (2007, p. 27 
Com o advento da Lei Complementar $n^{\circ}$ 123/2006, que regulamentou os princípios econômicos constitucionais, as atividades empresarias contempladas podem contar com serviços públicos menos burocráticos, que na opinião de Aragão:

(...) corresponderia os serviços públicos às atividades prestacionais em geral do Estado, ou seja, às funções que exerce para proporcionar diretamente aos indivíduos comodidades e utilidades, independentemente de poderem deles ser cobradas individualmente ou não, ou de serem de titularidade do Estado. ${ }^{14}$

O SEBRAE - Serviço Brasileiro de Apoio às Micro e Pequenas Empresas, atua objetivando desenvolver atividades relacionadas ao empreendedorismo voltadas às MPE brasileiras; essas atividades consistem em um serviço social autônomo que realizou estudos ao longo dos anos e constatou que os negócios provenientes das micro e pequenas empresas são responsáveis pela geração da maioria dos empregos formais no Brasil, constatou ainda que, após as medidas constitucionais de incentivo e proteção, as micro e pequenas empresas vem conquistando maior espaço no cenário econômico, como também as politicas de incentivo tem alcançado efeitos positivos na geração de novos empregos ${ }^{15}$.

Além de melhorar consideravelmente o acesso aos serviços públicos a LC 123/2006 possibilitou o pagamento de impostos a partir de alíquotas menores visando a manutenção de recursos financeiros alavancando a atividade e garantindo a permanência das empresas no mercado, contribuindo para o surgimento e manutenção de empregos.

\subsection{Contextos Político e Socioeconômico}

No presente estudo observar-se-á as características das MPEs sob uma ótica socioeconômica e política, e sob este aspecto pode-se afirmar que existem três concepções: a) MPE como iniciativa privada; MPE como alternativa ao desemprego; e c) MPE como categoria socioeconômica. ${ }^{16}$

Como iniciativa privada o empresário é colocado em evidencia como sendo um

\footnotetext{
${ }^{14}$ ARAGÃO, Alexandre Santos de. O Conceito de Serviços Públicos no Direito Constitucional Brasileiro. Revista Eletrônica de Direito Administrativo Econômico (REDAE, Salvador, IBDP, n 17, fev/mar/abr/2009. Disponível No site: www.direitodoestado.com.br. Acessado em 20 de agosto de 2015.

15 SEBRAE - Serviço Brasileiro de Apoio às Micro e Pequenas Empresas, Anuário do trabalho na micro e pequena empresa, Departamento Intersindical de Estatística e Estudos Socioeconômicos responsável pela elaboração da pesquisa, dos textos, tabelas, gráficos e mapas, 2015.296 p.

${ }^{16}$ MONTAÑO, Carlos E. Microempresa na era da globalização: uma abordagem histórico-crítica, ed. - São Paulo: Cortez, 2001, p. 25-26
} 
empreendedor capitalista, como outros tantos, diferenciando-se somente quanto ao porte e volume de negócios. ${ }^{17}$

As MPEs como alternativa ao desemprego são descritas pelo fato de que estas empresas estão presentes no mercado econômico de forma quantitativa e qualitativa, onde o incentivo ao empreendedorismo torna-se uma excelente estratégia estatal para a reestruturação produtiva, inserindo trabalhadores desempregados no mercado formal. Contudo, ao estado, surge a necessidade de proteger e promover facilidades e benefícios ${ }^{18}$ para sua sobrevivência.

Para caracterizar as MPEs como uma categoria socioeconômica e política são necessárias que estas participem de um contexto socioeconômico e seu relacionamento com as demais empresas seja político e econômico entre desiguais. ${ }^{19}$

O Estado social, desse modo, caracteriza-se por introduzir por meio da ordem constitucional um específico modelo de forte intervenção cujo modo de produção é pautado pela apropriação mista dos meios de produção e por um esquema de planejamento parcial em um sistema econômico predominantemente capitalista. ${ }^{20}$

Para que prevaleça o interesse coletivo sobre o individual busca-se suprir a necessidade de uma nova ordem pública econômica, a qual implica na fusão dos interesses políticos e econômicos, tornando-se “políticos-sociais', cuja medida é a defesa do crescimento econômico, da estabilidade financeira e do acesso a igualdade material. ${ }^{21}$

Antes nunca visto na história, ao Estado, foi conferida a função de democratizar a própria economia, melhor distribuindo os recursos disponíveis e proteger os que mais dependem de proteção e incentivo mediante suas necessidades sociais. ${ }^{22}$

$\mathrm{Na}$ opinião de Gabardo, é importante a prática estatal conjunta do planejamento econômico, político e social para proporcional o alcance de todos os cidadãos dos direitos fundamentais, senão vejamos:

Tão importante quanto o planejamento econômico de mercado propriamente dito são as práticas sociais e políticas, para caracterizar um Estado social. No seu núcleo

\footnotetext{
${ }^{17}$ Id. 2001, p. 25.

18 DUARTE, Edinei Magela. O Empreendedorismo nas Micro e Pequenas Empresas: Um Estudo de Caso Aplicado á Cidade de Pará de Minas - MG. Dissertação apresentada ao curso de Mestrado Profissional em Administração das Faculdades Pedro Leopoldo. 2013, p. 20. Disponível em: http://www.fpl.edu.br/2013/media/pdfs/mestrado/dissertacoes_2013/dissertacao_ednei_magela_duarte_2013.pdf. Acessado em: 20/12/2015.

19 MONTAÑO, Carlos E. 2001, p. 25.

${ }^{20}$ GABARDO, Emerson. Interesse público e subsidiariedade: o Estado e a sociedade civil para além do bem e do mal. Emerson Gabardo; prefácio de : Vera Karam de Chueiri; apresentação de Regina Maria Macedo Nery Ferrari. Belo Horizonte: Fórum. 2009. p. 166.

${ }^{21}$ Idem, 2009, 159.

22 Idem, 2009, 163.
} 
devem ser colocados os programas de redistribuição econômica. Por sua vez, a identificação da "política social" se faz por meio da alocação obrigatória de um sistema de organização e prestação de serviços nas áreas da saúde, trabalho, cultura e educação, além do estabelecimento de garantias para a população jovem, idosa e portadora de necessidades especiais. ${ }^{23}$

Como é possível vislumbrar, há conexão direta e interdependente entre os aspectos econômicos, sociais e políticos, e o Estado é o responsável para gerenciar de forma eficaz e eficientemente estes aspectos, promovendo a democratização da economia de forma igualitária a todos.

\section{A IMPORTÂNCIA DA MPE NA INCLUSÃO DO CIDADÃO AO MERCADO DE TRABALHO}

Diante das visíveis melhorias e oportunidades disponibilizadas às MPEs, por meio da legislação que prevê a proteção e o tratamento diferenciado, garantiu-se melhores condições para a sobrevida dessas empresas e acima de tudo a principal intenção é incentivar o cidadão tronar-se empreendedor, regularizando sua atividade, e a geração de novos empregos pelos micro e pequenos empreendedores.

Tendo em vista a grande importância para a economia do país, sendo possível destacar que as MPEs correspondem a parte do alicerce da economia onde são responsáveis por boa parte do desenvolvimento social e econômico, em especial ao acesso ao mercado de trabalho, torna-se imprescindível a abordagem de duas formas de inserção do indivíduo ao mercado de trabalho por meio das MPE: o empreendedorismo e o emprego formal.

\subsection{Empreendedorismo}

${ }^{23}$ GABARDO, 2009.p.166. 
A partir das oscilações da economia o mercado de trabalho se depara com a necessidade de adequar-se a realidade momentânea, ora disponibilizando trabalho formal ora fomentado o empreendedorismo.

O empreendedorismo é um processo pelo qual cria-se riquezas e promove o crescimento econômico, conforme os dizeres de Neto e Sales:

É um processo dinâmico de criação de riquezas incremental. A riqueza é criada por indivíduos que assumem maiores riscos em termos ativos, tempo, e perspectivas de carreira, para produzirem bens ou serviços através dos recursos que lhe são disponibilizados. 24

No inicio da década de 90 o empreendedorismo emergiu fortemente impulsionado pelas políticas de fomento, pelas novas leis protecionistas, em decorrência da privatização e do ajuste econômico. Todavia, referidas políticas fizeram com que os produtos estrangeiros ingressassem no Brasil, sob o argumento de que haveria uma maior competitividade empresarial. ${ }^{25}$

A figura do empreendedor é aquele que: apresenta novos conceitos; aponta para novas oportunidades; cria empreendimentos; disponibiliza recursos e tempo para gerenciá-los. Empreendedor é aquele que une: recursos, trabalho, bens diversos aumentando a valoração sobre estes. Modifica, inova e conduz a uma nova ordem. ${ }^{26}$

O empreendedor deve ter uma percepção geral e ampla do ambiente onde atua, propor algo novo, sendo a confiança uma característica primordial, uma vez que a qualquer momento podem ocorrer imprevistos. ${ }^{27}$

\footnotetext{
${ }^{24}$ NETO, S.P.; SALES, A. H. L., Empreendedorismo nas Micro e Pequenas Empresas no Brasil. Anais do ENANPAD - XXVIII, Encontro da Associação Nacional dos Programas de Pós-Graduação em Administração. Curitiba: ANPAD, 2004.

${ }^{25}$ GALESNE, A.; FENSTERSEIFER, J. E.; LAMB R. Decisões de Investimentos da Empresa. São Paulo: Atlas, 1999.

${ }^{26}$ LUECKE, R. Ferramentas para Empreendedores: ferramentas e técnicas para desenvolver e expandir seus negócios. Rio de Janeiro: Record, 2007, p. 29.

${ }^{27}$ HALLORAN, J.W. Por que os Empreendedores Falham. São Paulo: Makron Books, 1994.
} 
O surgimento de novas empresas em todo o país é crescente, tendo em vista o aumento da vontade de empreender, sendo que dentre elas as micro e pequenas empresas destacam-se como geradoras de emprego e renda, contribuindo para a economia nacional. ${ }^{28}$

Face a esta realidade é de suma importância a análise das políticas estatais de fomento voltadas para as MPEs sob a égide do acesso a atividade laborativa.

Muitas pessoas almejam sair da informalidade, e o empreendedorismo é uma das possibilidades a partir do momento em que há condições favoráveis para o surgimento de novas MPEs.

Em razão de estarem protegidas legalmente e ser possível usufruir dos serviços públicos de forma mais simplificadas, viabiliza-se a atividade do empreendedor informal a transformar sua atividade em uma micro empresa.

As MPEs possuem maior facilidades na obtenção simplificada de atendimento quanto a serviços públicos, pois visam a busca do desenvolvimento econômico empresarial e também pretendem contribuir para a estabilidade da economia como um todo.

No entendimento de Schirato serviços públicos são:

(...) aquelas atividades econômicas em sentido amplo prestadas pelo Estado com o objetivo de realizar suas atividades fundamentais e satisfazer o interesse coletivo, sob um regime total ou parcial de direito público, o que garante às atividades consideradas serviços públicos garantias e prerrogativas especiais. ${ }^{29}$

Portanto, mais que um incentivo ao particular, o fomento a novos empreendimentos disponibiliza a estrutura de serviços estatais para a satisfação do interesse coletivo que é o desenvolvimento da economia.

\footnotetext{
${ }^{28}$ MAROLLI, Gisele, Desenvolvimento Local: um estudo baseado na importância das Micro e Pequenas Empresas no Município de Pitanga/PR, Dissertação de Mestrado em Desenvolvimento Regional pela Universidade do Contestado (UnC), Canoinhas/SC. Disponível no site: http://www.unc.br/mestrado/editais/DISSERTACAO, acessado em 20 de dezembro de 2015.

29 SCHIRATO, Vitor Rhein. A regulação dos serviços públicos como instrumento para o desenvolvimento. Interesse Público, Belo Horizonte, v. 6, n. 30, mar. 2005. Disponível em: <http://bdjur.stj.jus.br/dspace/handle/2011/32953>. Acesso em: 06 dez. 2015.
} 
Quando o particular, ao ser inserido no mercado de trabalho por meio de uma atividade empresarial, consegue manter-se nesse mercado em razão de uma ou mais políticas públicas, verifica-se a crescente produção de bens e riquezas o que contribui positivamente para a estabilidade e/ou o desenvolvimento econômico em sentido amplo.

\subsection{Emprego e Formalidade}

O novo cenário econômico mundial transformou significativamente as estruturas empresariais existentes e por consequência o mercado de trabalho, evidenciando ainda mais a fragilidade das MPEs.

Aliando-se aos dispositivos legais que objetivam proteger e prestar atendimento diferenciado às MPEs, está o princípio constitucional do Pleno Emprego, este princípio está esculpido no inciso VIII do art. 170 da CF/88 que na visão de Nazar é um princípio de ordem econômica que visa a criar oportunidades de trabalho para que todos possam viver dignamente, eliminando ou atenuando o déficit empregatício. ${ }^{30}$

O desempenho positivo da economia do país nos últimos anos em conjunto com as políticas de crédito, fomentou o surgimento de MPE no Brasil, demonstrando a grande importância como também sua participação expressiva na estrutura produtiva. ${ }^{31}$

Na publicação de 2014, o SEBRAE publicou em seu anuário de Participação das Micro e Pequenas Empresas na Economia Brasileira o que segue:

As Micro e Pequenas Empresas (MPE) vêm progressivamente aumentando sua relevância na economia brasileira. Constatou-se que em termos agregados esta participação era de $21 \%$ em 1985, aumentou para $23 \%$ em 2001 e para $27 \%$ em 2011. Esta participação aumentou tanto em serviços como no comércio tendo se reduzido um pouco na atividade industrial, onde predominam médias e grandes empresas que se beneficiam de economias de escala. ${ }^{32}$

\footnotetext{
${ }^{30}$ NAZAR, Nelson, Direito Econômico, $3^{\text {a }}$ Ed.rev. ampl. E atual. São Paulo: Edipro, 2014.

${ }^{31}$ DUARTE, Edinei Magela. O Empreendedorismo nas Micro e Pequenas Empresas: Um Estudo de Caso Aplicado á Cidade de Pará de Minas - MG. Dissertação apresentada ao curso de Mestrado Profissional em Administração das Faculdades Pedro Leopoldo. 2013, p. 20. Disponível em: http://www.fpl.edu.br/2013/media/pdfs/mestrado/dissertacoes_2013/dissertacao_ednei_magela_duarte_2013.pdf. Acessado em: 20/12/2015.

${ }^{32}$ SEBRAE - Serviço Brasileiro de Apoio às Micro e Pequenas Empresas - Sebrae, Participação das Micro e Pequenas Empresas na Economia Brasileira, Unidade de Gestão Estratégica - UGE, Julho/2014. Disponível em http://www.sebrae.com.br/Sebrae/Portal, acessado em 20/12/2015.
} 
As MPEs representam uma parcela considerável da totalidade dos empreendimentos nacionais e podem ser a solução para o crescimento econômico e uma vez que estão imbuídas na luta contra problemas sociais, pois contribuem para a erradicação do desemprego e da pobreza, diminuição das desigualdades e proporcionam melhores condições de vida para os cidadãos.

Na década de 2000, as MPEs ultrapassaram os seis milhões de estabelecimentos, criando 6,1 milhões de empregos com Carteira de Trabalho assinada, sendo que em 2001, 43,5\% dos empregados possuíam carteira assinada, passando para 50,9\% em 2009, salienta ainda que os micro e pequenos empresários são responsáveis por mais da metade dos empregos existentes no país. ${ }^{33}$

Diante desta realidade, nota-se a real necessidade de implementação de políticas públicas objetivando fomentar a geração de emprego e renda a partir da formalização dos empreendimentos que estão à informalidade uma vez que as estatísticas apontam para este norte a alavancagem da economia e o efetivo cumprimento dos princípios econômicos inseridos na Constituição Federal de 1988.

\section{POLÍTICAS ESTATAIS DE INCENTIVO E FOMENTO A EMPREGABILIDADE - GERAÇÃO DE EMPREGOS POR MEIO DAS MPE}

\subsection{Critérios tipológicos de fomento}

Segundo Oliveira a variedade tipológica dos instrumentos de fomento administrativo atendem os seguintes critérios: a) critério de vontade, este critério se subdivide em fomento positivo - medidas que visam promover ou viabilizar a realização de certa atividade - e fomento negativo medidas com o fim de reduzir ou dificultar a realização de certa atividade; b) critério de vantagens que é subdivido em meios psicológicos - sugestionamentos -,

33 DUARTE, 2013, p. 20. Disponível em: http://www.fpl.edu.br/2013/media/pdfs/mestrado/ dissertacoes_2013/dissertacao_ednei_magela_duarte_2013.pdf. Acessado em: 20/12/2015. 
honoríficos - recompensas e reconhecimento público -, e econômicos - através de meios financeiras outorga-se vantagens pecuniária ao beneficiário. ${ }^{34}$

Em análise mais pormenorizada desta última variedade tipológica de instrumento de fomento administrativo, a econômica, estão: a) os meios creditícios ou meios econômicos em sentido estrito - linhas de crédito privilegiadas para determinado seguimento; b) os meios econômicos - entrega de subvenções e/ou outras espécies condicionadas a financiar atividades consideras de interesse público, estes podem ser diretos (subvenções) e indiretos (redução de alíquotas). ${ }^{35}$

O princípio da razoabilidade e da proporcionalidade impõem limitações no estabelecimento normativo e devida concretização administrativa de quaisquer modalidades de atividade fomentadora, desenvolvidos na seara da ordem constitucional econômica e social ${ }^{36}$ Para Oliveira "os princípios constitucionais da razoabilidade e da proporcionalidade são elementos chaves para garantir a atividade promocional ou de fomento." ${ }^{37}$

4.2 Meio econômico indireto de fomento - incentivos fiscais

Cada vez mais faz-se presente a participação do Estado como agente normativo, intervindo sobre o domínio econômico e social. Nesse sentido Gabardo assim aduz:

\begin{abstract}
A existência de um "poder ordenador" obviamente não é característica do momento moderno, mas acompanha a própria história da sociedade e é determinada pela mentalidade imanente ao grupo(...); o pai, o monarca, o senhor feudal, o parlamento, o governo, os juízes, o coronel. Várias formas de intervenção pública impostas, entre outros motivos, para evitar o abuso na satisfação dos interesses individuais ou no exercício de direitos e liberdades pelos particulares. ${ }^{38}$
\end{abstract}

A intervenção pode ocorrer com base em diferentes ferramentas, com destaque para as de natureza tributária. As normas jurídicas tributárias, quando utilizadas como incentivos para determinados comportamentos econômicos, revelam-se instrumentos potencialmente

\footnotetext{
${ }^{34}$ OLIVEIRA, Jóse Roberto Pimenta. Os princípios da razoabilidade e da proporcionalidade no direito administrativo brasileiro. São Paulo: Malheiros, 2006.

${ }^{35}$ Idem, pag. 524

${ }^{36}$ Idem, pag. 519.

37 Idem, pag. 524.

${ }^{38}$ GABARDO, 2009, p.156.
} 
aptos para alcançar finalidades do Estado, por meio de políticas fiscais, passíveis de valoração em termos de eficiência. ${ }^{39}$

O direito tributário nacional tem por finalidade buscar recursos financeiros de modo que o Estado possa promover o bem comum. Estabelece regras para a arrecadação e distribuição dos recursos no intuito de fomentar a atividade pública e privada.

Segundo o conceito estampado no artigo $3 .^{\circ}$ do CTN:

Art. 3. ${ }^{\circ}$ - Tributo é toda prestação pecuniária compulsória, em moeda ou cujo valor se possa exprimir, que não de ato ilícito, instituída em lei e cobrada mediante atividade administrativa constitua sanção plenamente vinculada.

Segundo Machado, os tributos assim considerados pela legislação possuem três funções: fiscal, parafiscal e extrafiscal ${ }^{40}$, portanto considera-se:

Fiscal ou fiscalidade é quando o principal objetivo é a arrecadação de recursos financeiros para o Estado e parafiscal ou parafiscalidade é quando o seu objetivo é a arrecadação de recursos para o custeio de atividades que em princípio, não integram funções próprias do Estado, mas este as desenvolve através de entidades específicas. $^{41}$

A extrafiscalidade é para Kelsen $(2006,48-49)$ como sendo "quando seu objetivo principal é a interferência no domínio econômico, buscando um efeito diverso da simples arrecadação de recursos financeiros. " 42

Avi-yonah citado por Assunção ${ }^{43}$ diz que "os tributos, além de terem a função arrecadatória de receitas para a manutenção do Estado, apresentam funções redistributiva e regulatória, No mesmo sentido Becker citado por Assunção afirma que:

(...) podendo, assim, oportunizar desde a redução de desigualdades sociais até a

\footnotetext{
${ }^{39}$ ASSUNÇÃO, Matheus Carneiro, Incentivos Fiscais e Desenvolvimento Econômico: a função das normas tributárias indutoras em tempos de crise, Finanças Públicas - XV Prêmio Tesouro Nacional - 2010, disponível no site http://www3.tesouro.fazenda.gov.br/Premio_TN/XVPremio/politica/MHpfceXVPTN/Tema_3_MH.pdf, acessado em 20/12/2015.

${ }^{40}$ MACHADO, Hugo de Brito, Função do tributo. Curso de Direito Tributário, 21 a . Edição, Editora malheiros, 2002.

41 Idem.

42 KELSEN, Hans. Teoria Pura do Direito. Trad.: MACHADO, João Baptista. 7. ed. São Paulo: Martins Fontes, 2006.
}

43 ASSUNÇÃO, 2010, disponível no $\quad$ site http://www3.tesouro.fazenda.gov.br/Premio_TN/XVPremio/politica/MHpfceXVPTN/Tema_3_MH.pdf, acessado em 20/12/2015. 
regulação de mercados. Nesse sentido, a principal finalidade de muitos tributos "não será a de instrumento de arrecadação de recursos para o custeio das despesas públicas, mas a de um instrumento de intervenção estatal no meio social e na economia privada" 44

O mecanismo adotado de arrecadação e distribuição de tributos pode ser melhor cumprir sua finalidade quando for possível utilizar os recursos provenientes da arrecadação de tributos locais para financiar atividades micro econômicas que fortaleçam a cadeia produtiva, as quais contribuem o desenvolvimento como um todo a partir da geração de empregos, inclusão no mercado formal e geração de bens e riquezas.

Os incentivos fiscais não podem ser postos a disposição dos cidadãos observando-se o regramento estabelecido pela Lei 123/2006 com o especial fim de buscar a efetivação dos princípios constitucionais que visam promover a vida com dignidade do homem.

A necessidade de promover o desenvolvimento econômico requer do indivíduo a ciência de quais são os instrumentos econômicos disponíveis e qual a melhor forma de utilizá-los, para isso a intensiva divulgação em massa dos benefícios proporcionados pela Lei Complementar 123/2006 é uma ação extremamente urgente no intuito de fomentar o empreendedorismo no Brasil.

Entre os benefícios concedidos pela LC 123/2006 correspondem a redução ou isenção de alíquotas de impostos. O poder público através destes incentivos fiscais busca atrair novos empreendimentos no intuito de gerar novos empregos, fomentar a economia e atrair novos investidores.

Porsse analisou a política de incentivo fiscal de alguns estados e conclui que as externalidades fiscais "têm um papel crucial nos resultados encontrados, pois permitem que os ganhos de bem estar do consumo privado, superem as perdas decorrentes da redução de provisão de bens públicos." 45

Diante do exposto, há de se notar que a política de incentivo fiscal é de grande valia para promover o desenvolvimento, contudo diante da necessidade de selecionar projetos que realmente cumpram sua contrapartida socioeconômica devem ser privilegiados aqueles projetos que possuam uma ideologia em consonância com a perspectiva sustentável.

Neste diapasão a tese de Oliveira coaduna-se com a tese de Porsse acima epigrafada, que além de descrever as formas possíveis de fomento afirma que esta atividade não é uma

\footnotetext{
${ }^{44}$ Idem

45 PORSSE, Alexandre Alves, HADDAD, Eduardo Amaral e RIBEIRO, Eduardo Pontual. Competição Tributária Regional, Externalidades Fiscais e Federalismo no Brasil: uma abordagem de equilíbrio geral computável. Brasília: ESAF. Monografia premiada em $2^{\circ}$ lugar no X Prêmio Tesouro Nacional. Tópicos Especiais de Finanças Públicas. Porto Alegre (RS), 2005.
} 
faculdade da administração, mas sim um dever, pois o desenvolvimento econômico é um objetivo/princípio constitucional caracterizando o fomento o meio pelo qual buscar-se-á a erradicação da pobreza e a inclusão social. ${ }^{46}$

Especificando ainda mais essa tese Daniel afirma que é perfeitamente possível o tratamento diferenciado voltado as MPEs que possuam uma atuação positiva quanto a utilização consciente dos recursos naturais e cumpram com sua função social empresarial, assim a interpretação constitucional da Lei $\mathrm{n}^{\circ}$ 12.349/2010 possibilita o desenvolvimento nacional sustentável, ao lado de garantir a isonomia e de propiciar a seleção mais vantajosa para a administração, o que implica dizer que é perfeitamente possível a preferencia por empresas que possuem uma certificação comprovando sua boa conduta ambiental. ${ }^{47}$

Como foi relatado a atual tendência é priorizar aquelas atividades que estão efetivamente preocupadas com a sustentabilidade dos recursos existentes. Esse critério já é permitido através da análise conjunta da legislação infraconstitucional com os princípios constitucionais voltados a economia. Essa exigência também contribui para a perpetuação do empreendimento na medida em que eleva o comprometimento e oportuniza um certo privilégio quanto a contratação junto administração pública.

Neste diapasão Castro e Lima afirmam que são cinco os fatores críticos do sucesso de uma cadeia produtiva:

\begin{abstract}
Equidade: diz respeito à maneira como se distribuem os benefícios resultantes dos produtos gerados e comercializados pela cadeia produtiva. Qualidade: refere-se à capacidade dos produtos da cadeia produtiva - em especial o produto final, a habitação - em satisfazer as necessidades dos consumidores. Eficiência: é a capacidade da cadeia produtiva em transformar recursos em produtos. Competitividade: capacidade da cadeia produtiva em colocar seus produtos em condições favoráveis de preço, comparativamente a produtos similares existentes no mercado, tanto nacional quanto internacional. E por fim, Sustentabilidade: capacidade da cadeia produtiva em gerar produtos e processos que são ambientalmente sustentáveis. ${ }^{48}$
\end{abstract}

No dicionário, "sustentabilidade" é definida como a condição daquilo que é sustentável, passível de sustentação. A definição de desenvolvimento sustentável pode ser expressa como a busca de atender às necessidades presentes, sem comprometer as

\footnotetext{
46 OLIVEIRA, Jóse Roberto Pimenta. Os princípios da razoabilidade e da proporcionalidade no direito administrativo brasileiro. São Paulo: Malheiros, 2006, pags. 514 a 539.

47 FERREIRA, Daniel. A Licitação pública no Brasil e sua nova finalidade legal: a promoção do desenvolvimento nacional sustentável. Belo Horizonte: Fórum, 2012. (p. 65-119)

${ }^{48}$ CASTRO, A. M. G. e LIMA, S. M. V. Prospecção tecnológica em cadeias produtivas industriais. Apostila. Ministério do Desenvolvimento, Indústria e Comércio Exterior. Brasília, 2001.
} 
necessidades das gerações futuras. ${ }^{49} \mathrm{O}$ termo foi incorporado pelo relatório da Comissão Mundial sobre Meio Ambiente e Desenvolvimento - Nosso Futuro Comum, publicado em 1987, também conhecido como Relatório de Brundtland”.

Nas palavras de Bruntlandt (1987):

\begin{abstract}
O conceito de desenvolvimento sustentável vem se espraiando por diversas áreas e atividades humanas, não se restringindo ao binômio meio ambiente/economia, ainda que, à época, este fosse o foco da formulação do conceito pelas instâncias das Nações Unidas. De fato, o desenvolvimento sustentável tem consistido em exigência para qualificação do processo educacional, da comunicação social, da carreira profissional, do funcionamento burocrático de órgãos estatais e, até mesmo, de estilos de vida individuais e de relacionamentos interpessoais. A sustentabilidade desponta como um ideal regulador na sociabilidade em geral, sem se limitar ao mercado, ao Estado ou à sociedade civil, conceituando um desenvolvimento que "satisfaz as necessidades presentes sem comprometer a capacidade das gerações futuras de suprir suas próprias necessidades. ${ }^{50}$
\end{abstract}

Assim é perfeitamente possível vislumbrar que as políticas estatais estão voltadas para o encorajamento do cidadão para que o mesmo busque desenvolver suas competências empreendedoras e, por conseguinte, que essas atividades individuais e/ou empresariais fomentem a abertura de novos postos de trabalhos.

Uma vez identificada a política de incentivo, qual seja a redução das alíquotas dos impostos, visto que esta modalidade tem demonstrado bons resultados no fomento a abertura de novas empresas. Ainda assim, torna-se necessário conscientizar o cidadão de sua função social, tanto no aspecto da boa utilização dos recursos ambientais disponíveis quanto na emergente necessidade de oportunizar a empregabilidade, para o alcance do sucesso empresarial e o consequente cumprimento do atendimento aos interesses da coletividade que é a estabilidade e desenvolvimento da economia.

Em que pese o incentivo fiscal ser uma abdicação direta de recursos financeiros dos quais a administração pública poderia dispor, de forma indireta esses recursos abdicados serão supridos em razão dos demais impostos gerados pela atividade dos empreendimentos viabilizados na região.

Torna-se evidente, que não basta recolher ao Estado o que lhe é de direito, mais sim usufruir dos meios legais para aplicar os impostos gerados por estes novos empreendimentos no intuito de estabelecer um ciclo econômico vital e perpétuo.

\footnotetext{
49 BRUNDTLANDT, Gro Harlem - Nosso Futuro Comum: Comissão mundial sobre meio ambiente e desenvolvimento, $2^{a}$ Edição, Editora Fundação Getulio Vargas, RJ, 1991

${ }^{50}$ BRUNDTLANDT, 1991
} 


\section{CONSIDERAÇÕES FINAIS}

A importância da MPE foi reconhecida constitucionalmente em razão de representar uma importante parcela dos empreendimentos responsáveis pelo desenvolvimento econômico. A estas empresas devem ser dispensados tratamento diferenciado quanto ao acesso ao serviço 
público e legalmente protegidas por se tratar de empresas em condições especiais. Os ditames constitucionais foram regulamentados pela Lei Complementar $n^{\circ} 123 / 2006$ qual trata das formas de proteção e diferenciação das demais.

Existem políticas públicas voltadas para o fomento do empreendedorismo e para a geração de empregos formais como forma de inclusão no ciclo econômico, entre os instrumentos está o incentivo fiscal como forma de redução de custos e atrativo para o surgimento de novas empresas, principalmente empreendimentos individuais e micro e pequenos negócios.

O estudo demonstra que as MPE viabilizam a maior parte dos empregos formais gerados no país. A crescente geração de empregos induz o crescimento econômico e contribui para a dignificação dos cidadãos tanto no aspecto pessoal quanto profissional, pois a empregabilidade traz maiores oportunidades de escolha.

A microempresa, a partir dos princípios constitucionais possui uma relevante importância, haja vista, a possibilidade de erradicar a pobreza e garantir o pleno acesso a participação no mercado de trabalho.

\section{REFERÊNCIAS}

ARAGÃO, Alexandre Santos de. O Conceito de Serviços Públicos no Direito Constitucional Brasileiro. Revista Eletrônica de Direito Administrativo Econômico (REDAE, Salvador, IBDP, $\mathrm{n}^{\mathrm{o}}$ 17, fev/mar/abr/2009. Disponível No site: www.direitodoestado.com.br. Acessado em 20 de agosto de 2015. 
ASSUNÇÃO, Matheus Carneiro, Incentivos Fiscais e Desenvolvimento Econômico: a função das normas tributárias indutoras em tempos de crise, Finanças Públicas - XV Prêmio Tesouro Nacional - 2010, disponível no site http://www3.tesouro.fazenda.gov.br/Premio_TN/XVPremio/politica/

MHpfceXVPTN/Tema_3_MH.pdf, acessado em 20/12/2015.

BRUNDTLANDT, Gro Harlem - Nosso Futuro Comum: Comissão mundial sobre meio ambiente e desenvolvimento, $2^{a}$ Edição, Editora Fundação Getulio Vargas, RJ, 1991

BRASIL. Constituição da República Federativa do Brasil de 1988. Disponível em: $<$ http://www.planalto.gov.br/ccivil_03/constituicao/ constituiçao.htm>. Acesso em $11 \mathrm{dez}$. 2015.

BRASIL, LEI no. 7.256, DE 27 DE NOVEMBRO DE 1984. Disponível em: http://www.planalto.gov.br/ccivil_03/ leis/_L7256.htm>. Acesso em 11 dez. 2015.

MOREIRA, Egon Bockmann ...

BRASIL. Lei $\mathbf{n}^{\circ} \mathbf{8 . 8 6 4}$ de 28 de Março de 1994. http://www.planalto.gov.br/ccivil_03/leis/L8864.htm>. Acesso em 11 dez. 2015.

BRASIL, Lei $\mathbf{n}^{\circ}$ 9.317, de 5 de Dezembro de 1996. http://www.planalto.gov.br/ccivil_03/leis/L9317.htm>. Acesso em 11 dez. 2015.

BRASIL, Lei $\mathbf{n}^{\mathbf{9}} \mathbf{9 . 8 4 1}$, de 5 de Outubro de 1999. http://www.planalto.gov.br/ccivil_03/leis/L9841.htm>. Acesso em 11 dez. 2015

BOMFIN, Ana Paula Rocha do. Comentários ao Estatuto Nacional das Microempresas e Empresas de Pequeno Porte - LC 123/2006. 1. Ed. Rio de Janeiro: Lumen Juris, 2007, p.2.

CASTRO, A. M. G. e LIMA, S. M. V. Prospecção tecnológica em cadeias produtivas industriais. Apostila. Ministério do Desenvolvimento, Indústria e Comércio Exterior. Brasília, 2001.

DUARTE, Edinei Magela. O Empreendedorismo nas Micro e Pequenas Empresas: Um Estudo de Caso Aplicado á Cidade de Pará de Minas - MG. Dissertação apresentada ao curso de Mestrado Profissional em Administração das Faculdades Pedro Leopoldo. 2013, p. 20.

Disponível

em:

http://www.fpl.edu.br/2013/media/pdfs/mestrado/dissertacoes_2013/dissertacao_ednei_magel a_duarte_2013.pdf. Acessado em: 20/12/2015.

FERREIRA, Daniel. A Licitação pública no Brasil e sua nova finalidade legal: a promoção do desenvolvimento nacional sustentável. Belo Horizonte: Fórum, 2012. (p. 65119)

GABARDO, Emerson. Interesse público e subsidiariedade: o Estado e a sociedade civil para além do bem e do mal. Emerson Gabardo; prefácio de : Vera Karam de Chueiri; apresentação de Regina Maria Macedo Nery Ferrari. Belo Horizonte: Fórum. 2009.166

GALESNE, A.; FENSTERSEIFER, J. E.; LAMB R. Decisões de Investimentos da Empresa. São Paulo: Atlas, 1999. 
LUECKE, R. Ferramentas para Empreendedores: ferramentas e técnicas para desenvolver e expandir seus negócios. Rio de Janeiro: Record, 2007, p. 29.

HACHEM, Daniel Wunder. Direito fundamental ao serviço público adequado e capacidade econômica do cidadão: repensando a universalidade do acesso à luz da igualdade material. A\&C - Revista de Direito Administrativo \& Constitucional, Belo Horizonte, ano 14. N. 55, jan./mar. 2014.

HALlORAN, J.W. Por que os Empreendedores Falham. São Paulo: Makron Books, 1994.

KELSEN, Hans. Teoria Pura do Direito. Trad.: MACHADO, João Baptista. 7. ed. São Paulo: Martins Fontes, 2006.

MACHADO, Hugo de Brito, Função do tributo. Curso de Direito Tributário, $21^{\mathrm{a}}$. Edição, Editora malheiros, 2002.

MAMEDE, Gladston. Comentários ao Estatuto Nacional da Microempresa e da Empresa de Pequeno Porte. 1. Ed. São Paulo: Atlas, 2007.Gladston Mamede (2007, p. 27

MONTAÑO, Carlos E. Microempresa na era da globalização: uma abordagem históricocrítica, ed. - São Paulo: Cortez, 2001

MARINS, James; BERTOLDI, Marcelo M. Simples Nacional: Estatuto da Microempresa e Empresa de Pequeno Porte Comentado. 1. Ed. São Paulo: Revista dos Tribunais, 2007.

MAROLLI, Gisele, Desenvolvimento Local: um estudo baseado na importância das Micro e Pequenas Empresas no Município de Pitanga/PR, Dissertação de Mestrado em Desenvolvimento Regional pela Universidade do Contestado (UnC), Canoinhas/SC. Disponível no site: http://www.unc.br/mestrado/editais/DISSERTACAO, acessado em 20 de dezembro de 2015.

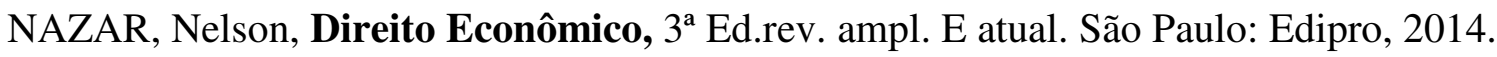

NETO, S.P.; SALES, A. H. L., Empreendedorismo nas Micro e Pequenas Empresas no Brasil. Anais do ENANPAD - XXVIII, Encontro da Associação Nacional dos Programas de Pós-Graduação em Administração. Curitiba: ANPAD, 2004.

OLIVEIRA, Jóse Roberto Pimenta. Os princípios da razoabilidade e da proporcionalidade no direito administrativo brasileiro. São Paulo: Malheiros, 2006.

PORSSE, Alexandre Alves, HADDAD, Eduardo Amaral e RIBEIRO, Eduardo Pontual. Competição Tributária Regional, Externalidades Fiscais e Federalismo no Brasil: uma abordagem de equilíbrio geral computável. Brasília: ESAF. Monografia premiada em $2^{\circ}$ lugar no X Prêmio Tesouro Nacional. Tópicos Especiais de Finanças Públicas. Porto Alegre (RS), 2005.

SEBRAE - Serviço Brasileiro de Apoio às Micro e Pequenas Empresas, Anuário do trabalho na micro e pequena empresa: Departamento Intersindical de Estatística e Estudos Socioeconômicos responsável pela elaboração da pesquisa, dos textos, tabelas, gráficos e mapas, 2015. 296 p. 
SCHIRATO, Vitor Rhein. A regulação dos serviços públicos como instrumento para o desenvolvimento. Interesse Público, Belo Horizonte, v. 6, n. 30, mar. 2005. Disponível em: <http://bdjur.stj.jus.br/dspace/handle/2011/32953>. Acesso em: 06 dez. 2015. 